\title{
BOUNDED RATIONALITY IN DECISION MAKING: AN ANALYSIS OF THE DECISION-MAKING BIASES
}

\author{
Ana Rita JORDÃO®1, Renato COSTA (D) 1, 3, Álvaro Lopes DIAS®1, $2^{*}$, \\ Leandro PEREIRA ${ }^{\circledR 1,3}$, José Pedro SANTOS®1 \\ ${ }^{1}$ ISCTE, DMOGG, Av. das Forças Armadas, Lisbon, Portugal \\ ${ }^{2}$ Universidade Lusófona, ECEO, Campo Grande 376, Lisbon, Portugal \\ ${ }^{3}$ Instituto Universitário de Lisboa (ISCTE-IUL), Business Research Unit (BRU-IUL), Lisboa, Portugal
}

Received 04 September 2019; accepted 29 October 2019

\begin{abstract}
Decision-making is a multidisciplinary and ubiquitous phenomenon in organizations, and it can be observed at the individual, group, and organizational levels. Decision making plays, however, an increasingly important role for the manager, whose cognitive competence is reflected in his ability to identify potential opportunities, to immediately detect and solve the problems he faces, and to predict and prevent future threats. Nevertheless, to what extent do managers of the most diverse sectors and industries continue to rely on false knowledge when they have better strategies at their disposal? The present article proposes, through the application of bibliographically based instruments, the diagnosis of three prominent biases - overconfidence, optimism, and anchoring effect - in managers of the Portuguese port sector, as well as also seeking to establish a comparative analysis with the conclusions already documented in relation to the Brazilian civil construction sector. In addition, and in view of the results obtained, this paper also provides a set of measures capable of contributing to the mitigation of the effects of these and other biases, and, in this way, to the improvement of the decisions of said managers.
\end{abstract}

Keywords: biases, overconfidence, optimism, anchoring effect, port sector.

JEL Classification: M12, M14, M54.

\section{Introduction}

Herbert Simon (1997) was one of the first authors to recognize that while the homos economicus intends to deal with the real world in all its complexity, the manager recognizes that the perceived world is nothing more than a drastically simplified model of the confusion and complication that surround us. This notion implies that managers, when making decisions, apply basic principles that do not occupy them much time for reflection. According to the author, such simplification can lead to errors but it also derives from the Man's nature, and there is no other realistic alternative to the limitations of reason and human knowledge. As Thaler (2016) states, "The reader knows, and I know, that we do not live in a world of homos economicus. We live in a world of human beings" (p. 21).

Acknowledging Man's time and cognitive constraints, Tversky and Kahneman (1974) listed a set of heuristics that allow individuals to produce judgments easily, quickly, and intuitively. These mental tools are vastly useful to managers who, given the urgency of decision making, are now able to save their time and cognitive effort without significant quality loss in their decisions. However, the nature of the use of heuristics - predominantly unconscious and intuitive - can prompt them to make considerable and predictable errors of judgment called biases.

The natural human susceptibility to biased thinking often leads people to produce irrational decisions even when all relevant facts and information are readily available to them (Frank, 2010). Likewise, managers, who are often seen as intelligent and generally successful people, may see their potential seriously compromised by the bias of their judgments.

For this reason, and in order to contribute to both the study in a national context as well as to the availability of useful tools for the improvement of managers' decisions, this article proposes the investigation of three well documented biases - overconfidence, optimism, and anchoring effect - on a sample of managers of the Portuguese port sector. In addition, and in view of the conclusions of

*Corresponding author. E-mail: alvaro.dias1@gmail.com 
Feitosa (2010) regarding the manifestation of these three biases in managers of the Brazilian civil construction sector, this paper also proposes a comparative analysis between the two sectors in order to identify possible behaviour convergences and/or divergences.

The objectives of this study can therefore be defined in three main points:

1. To diagnose the presence of overconfidence, optimism and anchoring effect in managers of the port sector;

2. To establish comparative links between the results of the diagnosis of managers of the port sector with bibliographically justified conclusions regarding managers of the construction sector in Brazil;

3. In the event of confirmation of any of the three biases, to provide established guidelines and recommendations in order to mitigate their impacts.

The three stated objectives will be fulfilled throughout the subsequent sections of the paper. In particular, the next section introduces the theoretical framework of the research topic, elucidating the reader about its main concepts and ideas. Next, it's clarified the pertinence of the study of the three biases, as well as the problem-related questions the paper proposes to answer. Moreover, it's presented the research model of this investigation (i.e. evaluation tools applied), together with a picture of the Portuguese port sector and its growing importance in the national economy, and the conclusions already recorded by Feitosa (2010). Lastly, the obtained results are analysed and compared to the reality observed in the construction sector in Brazil, and a set of recommendations to prevent possible bias detected in the judgment of the managers of the sample under analysis is also made available.

\section{Theoretical background}

As previously mentioned, heuristics are generally useful and efficient tools, allowing individuals to, most of the time, save their cognitive effort and other resources spent on decision making. Nonetheless, a blind reliance in intuition can lead even the brightest individuals to apply such mental shortcuts in an erroneous way, eventually making considerable errors of judgment. These systematic and predictable errors are called biases.

\subsection{Overconfidence}

Bazerman and Moore (2013) suggest that overconfidence can be considered the father of all biases. Firstly, because its effects are the most dominant, deep, and destructive of the set of previously documented biases. Griffing and Varey (1996) go as far as to claim that overconfidence is not only accentuated but almost universal, while DeBondt and Thaler (1995) add that this is arguably the most robust bias ever studied in the psychology of judgment. Secondly, because overconfidence acts as the driver for many of the remaining biases.
Extensive research demonstrates that individuals are overconfident in their beliefs, even if unfounded. More precisely, they tend to place too much certainty in their judgments (overprecision), to believe that they are better, in a series of desirable attributes, than what they really are (overestimation) and to judge themselves superior to others in certain dimensions (overplacement).

Some authors argue that overconfidence, and some positive illusions in particular, can sometimes be beneficial in the sense that they improve and protect the person's self-esteem, they increase their commitment and individual content, and also instil persistence in the face of difficult tasks or uncontrollable and adverse situations (Bi et al., 2016). Even so, there is no evidence that positive illusions lead to better decisions, quite the contrary.

According to Thaler (2005), overconfidence can be observed in two ways: (1) the confidence ranges that individuals define for their quantitative estimates are generally too narrow (e.g. in their investigation, Alpert and Raiffa (1982) observed that the $98 \%$ confidence intervals of the decision-makers only included the correct answer in about $60 \%$ of the time); and (2) individuals are poorly calibrated in the calculation of probabilities (e.g. according to Fischhoff et al. (1977), of the events that we are sure to happen only $80 \%$ end up occurring).

Good managers are known for being able to make a realistic assessment of the risks, dangers, and failures, especially their own. Yet, overconfidence unconsciously and systematically harms the manager's decision making (Dedu et al., 2012). This bias has been shown to be responsible for situations such stock market bubbles (Nofsinger, 2005), the continuous bet on acquisitions and organizational mergers despite their failure rate (Malmendier \& Tate, 2015), or even the high level of entrepreneurial initiatives in businesses that soon go bankrupt (Libby \& Rennekamp, 2012).

\subsection{Optimism}

The tendency to overestimate the positivism of the future is known as unrealistic optimism. Weinstein (1980) notes that most people have overly optimistic ideas about their skills and future expectations. They tend to judge the probability of experiencing positive events throughout their lives as above average, while underestimating their susceptibility to unpleasant situations.

In addition, the illusion of control also seems to play a key role in building overly optimistic views, thus influencing the commitments we make and therefore compromising our ability to achieve the goals we have set out (Baker \& Wurgler, 2004). Effects of this nature are further exacerbated by the high commitment of individuals towards their projects or expectations (Meyer, 2014).

In the business domain, optimistic overvaluation has already been associated with several strategic decisions, such as the level at which managers are willing to indebt their companies (Heaton, 2002; Hackbarth, 2004; Fairchild, 2005; Malmendier et al., 2011), and why deadlines 
and budgets are systematically exceeded (Buehler et al., 1994; Siemiatycki, 2010). In the latter, this tendency, called planning fallacy, results from overestimating human speed to complete projects and tasks, as well as from the lack of anticipation of difficulties that may arise during the process.

Although optimism can be studied in terms of situational variations, its analysis is usually made in terms of individual differences: optimistic people tend to have positive expectations about their future, as opposed to pessimistic people who tend to expect the worst. For this reason, much of the research on this topic of human behaviour resorted to the application of the Life Orientation Test - LOT (Scheier \& Carver, 1988), in which generalized expectations are analysed for positive events versus negative events.

\subsection{Anchoring effect}

Tversky and Kahneman (1974) argue that when making quantitative estimates people have a starting point, sometimes an arbitrary value, to which they make adjustments until they reach a final solution. The authors suggest, however, that such adjustments are typically insufficient, resulting in the produced estimates being anchored to their reference values. This tendency for our judgments to be overly influenced by opinions or initial information is called the anchoring effect.

The anchor may be externally imposed (e.g. suggested in the problem) or developed by the decision maker (e.g. an initial estimate) (Epley, 2004). In both cases, the adjustments made to it are typically insufficient since the individual is biased in his search for information, displaying preference for data that conforms to the presented anchor. Consequently, different starting points will give rise to different estimates.

Research shows that this phenomenon is also observable in the decision-making of managers, especially in negotiation situations. The simple act of exposing an individual to an extremely high price results in an increase of the value that individual is willing to pay for a good (Galinsky \& Mussweiler, 2001; Gunia et al., 2013) even if that good belongs to a different category from the one that was introduced as an anchor. Other domains in which the anchoring effect was detected include pricing decisions (Mussweiler et al., 2000), financial investment decisions (Serfas, 2011), probability estimates (Tversky \& Kahneman, 1974), performance forecast (Schade \& Koellinger, 2007) and even on general knowledge questions (Jacowitz \& Kahneman, 1995).

\section{Approach}

Establishing the bridge to the literature review presented above, the problem-related questions (PQ) presented here, and to be developed and answered in the following sections, aim at solving the objectives initially set, namely, to ascertaining the susceptibility of managers in the port sector to the three biases, and to compare such effects with Feitosa's (2010) observations in relation to the Brazilian civil construction sector. For this reason, each problemrelated questions is composed of two distinct questions which, although connected, seek to fulfil these two different objectives.

\subsection{Overconfidence}

Overconfidence seems to be universal and it can be observed independently of the academic and gender background of the decision maker. Malmendier and Tate (2015) state that changes in perceived risk resulting from overconfidence are observable even in top managers, in these cases preventing them from carrying out reliable analyses to support their strategic decisions. Moreover, Libby and Rennekamp (2012) find that more confident managers tend to have a more optimistic view of the future performance of the organization, to which Dedu et al. (2012) add that overconfident managers tend to overestimate their cash-flows, and to accept above optimal debt levels.

Thus, although some authors defend the beneficial effects of overconfidence by pointing out that more confident individuals also tend to be more persistent (Bi et al., 2016), there is already extensive evidence that this phenomenon can result in poor decisions made in both the business and financial environment. It is, therefore, essential to understand the extent to which decisions within organizations are influenced by the excessive confidence of their professionals, and seeking to minimize the risks associated with them. This topic introduces the first problem-related question of the present study:

PQ1 - Are managers in the Portuguese port sector susceptible to the overconfidence bias? (PQ1a) How do its effects compare with those observed in the Brazilian construction sector? (PQ1b)

\subsection{Optimism}

The literature on decision-making and behavioural finance points out that optimistic bias is also often observed in organizational managers, mainly regarding their perceptions of success and risk associated with their businesses (Hackbarth, 2004). In particular, it has already been shown that optimism can materially influence the decisions managers make on planning, investment and financing matters (Baker \& Wurgler, 2004).

This bias is considered to be one of the main causes for serious failures both in setting deadlines (Buehler et al., 1994) and in cost-benefit analysis (Siemiatycki, 2010). Furthermore, this is observable not only in the initial phases of the projects, but also throughout the remaining stages, and it may even lead to an excessive feeling of commitment of the manager (Meyer, 2014). On the other hand, with regard to the capital structure of companies, some authors suggest that optimistic managers tend to have higher levels of debt (Hackbarth, 2004; Malmendier 
et al., 2011), while others argue the opposite (Heaton, 2002; Fairchild, 2005). Having said this, such observations assert to the relevance of the second problem-related question to be explored in this study:

PQ2 - Are managers in the Portuguese port sector susceptible to the optimism bias? (PQ2a) How do its effects compare with those observed in the Brazilian construction sector? (PQ2b)

\subsection{Anchoring effect}

Lastly, the literature on the anchoring effect also underlines its immense evidence regarding the decision-making process of managers at both strategic and financial levels. In particular, the phenomenon of the anchoring effect has been largely studied in the context of professional's forecasting, having been observed that this bias may result in poor estimates of variables such as the future performance of companies and their new businesses (Schade \& Koellinger, 2007), as well as the return of certain financial investments (Serfas, 2011). On the other hand, it is also worth noting the robustness of this bias in a variety of negotiation contexts where, as a rule, unacceptable offers are introduced as anchors (Bazerman et al., 2000; Galinsky \& Mussweiler, 2001; Gunia et al., 2013).

In short, judgmental vulnerabilities of this nature can have serious consequences both at the individual and organizational levels, which make it important to detect them in order to prevent their impacts. This leads us to the third and final problem-related question of this study:

PQ3 - Are managers in the Portuguese port sector susceptible to the anchoring bias? (PQ3a) How do its effects compare with those observed in the Brazilian construction sector? (PQ3b)

\section{Methodology}

In order to meet the outlined objectives and to address the set out problem-related questions, it was strictly necessary to collect and analyse data directly from primary sources. This was accomplished through the form of a questionnaire survey directed at a set of managers from different organizations (and management levels) of the Portuguese port sector.

More specifically, in a first stage (preliminary phase) part of the sample received questionnaires with open response questions, and, in a second stage (main phase), every subject of the sample received questionnaires composed of both open and closed response questions. Furthermore, in the main phase, the two models of structured questionnaires sent out, although composed by the same three evaluation instruments, varied in the form of their last set of questions. Each instrument was designed to diagnose one of the three biases and to solve its respective problem-related questions, having thus been adapted from different literary sources. Additionally, the results obtained in the preliminary phase were used to elaborate one of the instruments included in the final questionnaire models, as explained in the next sections of this paper.

It is also important to point out that special attention was given to keeping the instruments as faithful as possible to those applied by Feitosa (2010) in his research on the Brazilian civil construction sector, with corrections being made only when necessary and as a consequence of the familiarity of the topics and issues presented.

\subsection{Overconfidence test}

As a means to examine the presence of the overconfidence bias in the sample (PQ1a), the investigation applied the proposals advanced by Gigerenzer et al. (1991) and Klayman et al. (1999), whose models are based on the definition of overconfidence given by Gigerenzer et al. (1991, p. 79) which associates said bias to when "judgments of confidence are greater than the relative frequencies of correct answers."

Under this notion, the authors propose a measure of overconfidence corresponding to the difference between the individuals' estimated average confidence levels (confidence level, $C L$ ) and their relative frequency of correct responses (accuracy rate, $A R$ ):

Overconfidence $=C L-A R$ (negative values of this indicator imply the presence of underconfidence).

In addition, the authors present an experimental model of confidence evaluation based on tasks of dichotomous choice, with the participants being asked to answer questions of two alternatives and to indicate the confidence level they associate to the certainty of having selected the correct answer. Subsequently, the answers are grouped by their respective categories of confidence, and the relative frequencies of correct answers are calculated for each of these categories. Overconfidence will be observed whenever the confidence judgments are higher than the correct responses relative frequencies.

By form of simplification, the overconfidence test presented in the questionnaire applied by Feitosa (2010) contained only 10 dichotomous questions. This model was maintained, for purposes of comparability, as well as the questions to be presented to the participants, which were adjusted only when necessary to ensure the feasibility of the study.

Thus, the test of overconfidence applied in this paper contemplated 10 questions of general culture, in which participants were asked to select the solution that they believed to be correct. After choosing the option that was preferred to them, each question was accompanied by a confidence scale of seven intervals ([50\%], [51\%-59\%], [60\%-69\%], [70\%-79\%], [80\%-89\%], [90\%-99\%] and [100\%]), where participants should assess the level of confidence estimated for the stated response. Having been informed that the correct answer to any of the questions was included in the two available alternatives, participants should note that a $50 \%$ confidence level corresponds to a 
random guess, while a $100 \%$ confidence level corresponds to the certainty of having selected the correct answer.

These values were then transformed as a function of the midpoint of each class - that is, $[50 \%]=5,[51-59 \%]=$ $5.5,[60 \%-69 \%]=6.45,[70 \%-79 \%]=7.45,[80-89 \%]=$ $8.45,[90-99 \%]=9.45$ and $[100 \%]=10$. Naturally, the mean of the transformed values in the 10 questions corresponded to $C L$, that is, the general level of confidence observed in the sample, while the accuracy rate $(A R)$ was determined by the average number of questions correctly answered by the respondents.

\subsection{Optimism test}

In order to verify the incidence of the optimism bias (PQ2a), it was applied the most frequently used research model - the Life Orientation Test (LOT) -, originally proposed by Scheier and Carver (1988) and later revised by the same authors (Scheier et al., 1994).

In the revised version of this test (LOT-R), the model used in this study, individuals were asked to indicate their degree of agreement with different statements by using a 5 -point Likert scale ( $0=$ "I strongly disagree", 1 = "I disagree", 2 = "I do not agree nor disagree", 3 = "I agree", and $4=$ "I totally agree"). The ten statements contemplated in the test (Scheier et al., 1994) included 3 items formulated in a positive direction (statements 1,4 and 10), 3 negatively formulated items (statements 3, 7 and 9) and 4 neutral items (statements 2, 5,6 and 8). The neutral questions (filler questions) did not aim at the analysis of the development of life orientation and were not to be included in the data analysis.

After reversing the scale in the negative statements, the scores were summed up to result in a certain level of optimism. Consequently, the higher the overall score, the greater the degree of optimism manifested. In this case, the global scale ranged from 0 to 24 , since the scoring of the neutral statements was not used for analysis purposes.

\subsection{Anchoring effect test}

The experimental-standard model for the analysis of the anchoring effect is based on the accomplishment of two consecutive tasks: the participants are firstly asked to make comparative judgments between an uncertain amount to be estimated (target value) and the anchor value (i.e. if the former is lower or higher than the latter), and then asked to make an absolute estimate of the effective quantity in question (Tversky \& Kahneman, 1974).

Furthermore, the method proposed by Jacowitz and Kahneman (1995) introduces the use of a parameter as measure of the anchoring effect in such estimation tasks, thus adopting the form of an experimental procedure that requires the analysis of three groups taken from the same population: the calibration group (CG), the highanchored group (AG) and the low-anchored group $(\mathrm{aG})$. The calibration group (CG) provides estimates for a set of uncertain quantities without any mention of the anchor, while the individuals of the high-anchored $(A G)$ and lowanchored $(a G)$ groups make their estimates (for the same set of questions) after making a comparison judgment with a value that is presented to them (high and low anchor, respectively). The anchors on these last two groups are, in turn, determined from the position in the calibration group's estimates distribution - the high anchor corresponds to the 85th percentile of this distribution while the low anchor corresponds to its 15 th percentile.

The anchoring effect is displayed whenever the groups exposed to the anchors ( $A G$ and $a G$ ) tend to produce estimates close to these values. For descriptive analysis of the presence of the bias (PQ3a), it is used an anchoring index $(A I)$ that measures the movement of the median estimate of individuals from the anchored groups towards the anchor they were presented with (Jacowitz \& Kahneman, 1995):

$$
A I=\frac{\text { Median }_{A G}-\text { Median }_{a G}}{\text { High Anchor }- \text { Low Anchor }} .
$$

Plausible values or this indicator range from 0 (no anchoring effect) to 1 (the estimates of the anchored individuals coinciding with the anchors provided). Values greater than 1 are, however, still possible.

In addition, in order to perform a more complete statistical analysis, the authors propose the transformation of the two anchoring groups' estimates into estimates corresponding to those of the calibration group (Jacowitz \& Kahneman, 1995). This procedure aims to allow for statistical comparisons of the observed anchoring effect between different samples (PQ3b).

The standardization of the AG and aG group estimates according to the median values of the calibration group entails that estimates equal to the median value of this group are transformed into 50, while estimates above or below the minimum estimates of the CG are transformed into 100 and 0 , respectively. The remaining estimates are standardized as follows:

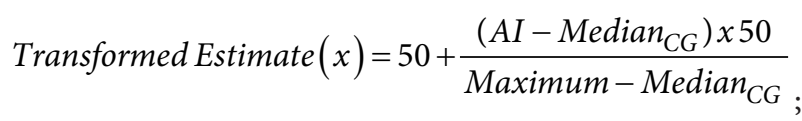

(for values between the maximum value and median of the $C G$ )

Transformed Estimate $(x)=\frac{\left(\text { AI }- \text { Minimum }_{G C}\right) \times 50}{\operatorname{Median}_{G C}-\text { Minimum }_{\text {inim }}}$.

(for values between the median and minimum value of the $C G$ )

As defined in the model of Jacowitz and Kahneman (1995), three separate questionnaires were produced and analysed in present investigation: a preliminary questionnaire and two final questionnaires. The preliminary questionnaire corresponded to the calibration group's information gathering stage, in this case solely consisting of the 5 questions to be incorporated in the anchoring effect test. In turn, the two final questionnaires, produced 
in the light of the results of their antecedent, included test instruments for each of the three biases under study, different only in the form of the test to the anchoring effect one questionnaire contemplated the high anchor and the other, the anchor low.

Table 1 shows the median and percentiles of the estimates produced by the individuals of the calibration group.

Table 1. Descriptive statistics of the calibration group

\begin{tabular}{|l|c|c|c|c|c|}
\hline \multicolumn{1}{|c|}{$n=41$} & $\mathrm{Q}_{1}$ & $\mathrm{Q}_{2}$ & $\mathrm{Q}_{3}$ & $\mathrm{Q}_{4}$ & $\mathrm{Q}_{5}$ \\
\hline Median & 2,000 & 8,000 & 400 & 700 & 90 \\
\hline Maximum & 100,000 & 800,000 & 900 & 3,400 & 5,000 \\
\hline Minimum & 100 & 1,700 & 150 & 15 & 10 \\
\hline $15^{\text {th }}$ Percentil & 400 & 3,200 & 300 & 100 & 25 \\
\hline $85^{\text {th }}$ Percentil & 7,000 & 11,200 & 500 & 1,900 & 300 \\
\hline
\end{tabular}

\subsection{Brazilian civil construction sector observations}

In his research, Feitosa (2010) engaged on the study of the influence of heuristics and biases in decision-making of managers in the Brazilian civil construction sector. Thus, he proceeded to diagnose the presence of overconfidence, optimism and anchoring effect in the managers of the Energy Directory of Construções e Comércio Camargo Corrêa (CCCC), S.A., a company present in the Brazilian market of engineering and construction since 1955, and that, as of 2010, had a market share of around $40 \%$ (Feitosa, 2010).

With this purpose, the decision attitudes of a sample of 84 managers were analysed through a questionnaire composed of three evaluation instruments that were identical in their form to those applied in this paper. From his investigation the author concluded that, in the first place, the managers of the company under analysis were overconfident in their estimates, with a non-parametric test showing that the managers' confidence level $(C L)$ was significantly higher than their accuracy rate $(A R)$ in the ten presented questions.

The managers were, on the other hand, more optimistic than other groups of economic agents. The sample registered an overall average score of 18.25 in the TOV-R, with a parametric test revealing this value to be significantly higher than 17.66, the score recorded by Bandeira et al. (2002) in relation to the Brazilian population in general.

Finally, the author observed that the managers' estimates were heavily influenced by the anchors to which they were exposed. The overall mean of the anchoring index $(A I)$ of the sample was 0.43 , meaning that, in comparison with the estimates of the calibration group, the medians of the managers' estimates exposed to the anchors moved $43 \%$ towards these very same values. Moreover, through the analysis of the median of the transformed estimates it was possible to verify that, in the whole test, the anchoring effect was superior with the low anchors than with the high anchors: the median of the transformed values was 51.58 for the group exposed to the high anchor $(A G)$ and 33.31 for the low anchor group $(a G)$. This fact was also proven by the application of a non-parametric test.

\subsection{Portuguese port sector}

According to Autoridade da Concorrência (ADC, 2015, p. 6), national ports "play a role that goes beyond their direct contribution to the economy and job creation". These constitute, above all, support to the economic activities developed in Portugal, acting as point of connection of the various logistic and international transport networks, and contributing, in this way, to facilitate the integration of Portuguese industries in the increasingly competitive international markets.

As expected, in 2016, and according to INE (2016), maritime transport stood out in foreign trade flows, representing around $58.3 \%$ of the international traffic volume in Portugal. In that same year, the movement of goods in the national ports amounted to 91.3 million tons, registering a growth of $5.1 \%$ over the previous period.

Naturally, international traffic accounts for a large part of the total volume of goods handled in Portuguese ports - around $83.7 \%$ of the total in 2016. It is also worth noting that the great preponderance of maritime transport is reflected in imports, essentially due to the strong dependence of the Portuguese economy on fossil-based raw materials needed to produce energy (i.e. crude oil, coal and natural gas), and cereals for the agri-food industry, both of which are mainly purchased from other continents.

In terms of geography, the Portuguese continental port system is composed of nine commercial ports, five of which constituting the main port system - Ports of Leixões, Aveiro, Lisbon, Setúbal and Sines -, with the remaining four composing the secondary port system Ports of Viana do Castelo, Figueira da Foz, Faro and Portimão. The autonomous regions also count with four ports located in Azores (Ports of Ponta Delgada, Horta, Flores and Praia da Vitória) and three ports in Madeira (Ports of Funchal, Porto Santo and Caniçal).

Overall, the mainland's commercial ports transported a total of 88.1 million tonnes of cargo in 2016, the highest value ever and around 5\% above the amount recorded in 2015. This growth was due solely to the positive performance of the Port of Sines during this period $(+16.6 \%)$, making this port the absolute national leader in terms of volume quotas of goods traded (a share of 54.6\%). Port of Leixões followed, accounting for $19.2 \%$ of the total volume of goods handled, next it was the Port of Lisbon with 10.6\%, Setúbal (7.6\%) and Aveiro (5.2\%).

With regard to port terminal operators in mainland ports (both public and private terminals), it is important to note that a significant number them are integrated in two economic groups with a prominent position in cargo handling in the port terminals, namely the Mota-Engil Group (currently present in the Ports of Aveiro, Figueira 
da Foz, Leixões, Lisbon and Setúbal, in the form of companies such as LISCONT, SOCARPORT, TCL, SOTAGUS, TERSADO and SADOPORT) and the ETE Group (present in the Ports of Leixões, Aveiro, Lisbon, Setúbal and Sines, through companies such as TCGL, TCL, Empresa de Tráfego e Estiva - ETE, S.A., OPERLIS, ATLANPORT, TERSADO, PORTSINES and AVEIPORT). It should also be highlighted the role played by Galp Energia Group, which through its strong presence in the ports serving the two Galp refineries (Port of Leixões and Porto de Sines) was responsible for about $77 \%$ of the movement in the same year of liquid bulks in all continental ports.

\subsection{Sample}

As aforementioned, the present investigation was based on a set of primary sources. Namely, at the time of the final survey, 77 questionnaires were duly completed by a group of managers from different hierarchy levels and organizations of the Portuguese port sector. This scope intended to include professionals from organizations from the multiple relevant geographic areas of the sector and, on the other hand, professionals whose positions and management functions were relevant to the subject of the study.

With that in mind, the sample was mostly composed by top managers and mid-level managers (39\% in both cases), with the first-line manager category being relatively less representative (22\%). Additionally, of the group of 77 respondents, it should be underlined the predominance of male individuals and participants with higher education (around $78 \%$ in both cases), although with a relative balance in respect to the indicator of age - the class with the highest prevalence was the 56 to 65 years with only about $33 \%$, and $50 \%$ of the individuals had a maximum age of 52 years.

On the other hand, in terms of the organizations contemplated in the sample, the geographical range was broad, having included organizations from all continental ports except for the Port of Viana do Castelo. In this regard, more than half of the sample refers to the participation of managers who work in APSS (Administration of Ports of Setúbal and Sesimbra), S.A. (26\%), ETE, S.A. (16\%), TCGL, S.A. (12\%), and TSA, Lda. (10\%). The remaining organizations, PORTSINES, S.A. (8\%), LISCONT, S.A. (8\%), TMB, S.A. (8\%), AVEIPORT, S.A. (4\%), and SETEFRETE, S.A. (3\%), presented a lower incidence in the sample.

\section{Results and discussion}

\subsection{Overconfidence test}

Attending the first problem-related question (PQ1a and PQ1b), a descriptive analysis of the answers to the ten questions of the overconfidence test suggests that the level of confidence that the surveyed managers place in their knowledge exceeds their actual capabilities (Table 2). In addition, on average, the managers in the sample believed to have answered correctly on at least 8 of the 10 questions provided to them, when in reality they only guessed right in a little less than 6 .

Moreover, as previously noted by Feitosa (2010), the standard deviation of the variable is considerably higher than the standard deviation of the variable, which indicates that the managers' confidence estimates on their judgments are more homogeneous than their accuracy. This data suggests that, besides being overconfident, managers are also homogeneous when it comes to their confidence estimates (Feitosa, 2010).

Table 2. Descriptive statistics of the calibration group

\begin{tabular}{|l|c|c|}
\hline \multicolumn{1}{|c|}{$n=77$} & $A R$ & $C L$ \\
\hline Mean & 5.99 & 8.09 \\
\hline Median & 7.00 & 8.08 \\
\hline Maximum & 10.00 & 10.00 \\
\hline Minimum & 0.00 & 6.17 \\
\hline Standard Deviation & 2.46 & 0.91 \\
\hline
\end{tabular}

Results obtained by performing a Wilcoxon Test for the equality of two means $(Z=-6.079$ and Sig $=0.000)$ allow us to conclude that the equality hypothesis between the means of the variables and is rejected at a confidence interval of $99 \%^{1}$, and that values associated to the variable are significantly higher than the values associated with the variable, which attests to the existence of overconfidence in the managers of the sample.

These results corroborate the observations already made by Feitosa (2010) in relation to the managers of the Brazilian civil construction sector, particularly with very similar values. However, it should be noted that there is a slight difference between the average values of correct answers recorded, which is lower in the sample of managers in the Portuguese port sector (5.99 compared to the 6.43 score in the Brazilian construction sector), although with similar averages of confidence levels (8.09 and 8.08, respectively).

\subsection{Optimism test}

Considering the second problem-related question (PQ2a and PQ2b), a preliminary descriptive analysis of the results obtained in the diagnostic tool for the bias of optimism, specifically the variable LOT-R, shows that the mean score of the sample registers a value of 16.94, suggesting the presence of this bias in the managers of the sector under study.

The mean score of the sample analyzed here is, however, slightly lower than that observed by Feitosa (2010) 18.25 -, although closer to the average score observed by Bandeira et al. (2002) - 17.66. In spite of this, it can be seen that, like in Feitosa's (2010) observations, the average

\footnotetext{
1 For reasons of comparability to Feitosa (2010), all results obtained in parametric and non-parametric tests presented here were performed at a confidence interval of $99 \%$.
} 
score of this sample (16.94) and its median (17.00) are quite close (Table 3 ).

Table 3. Descriptive statistics of the optimism test variables

\begin{tabular}{|l|c|}
\hline \multicolumn{1}{|c|}{$n=77$} & LOT-R \\
\hline Mean & 16.94 \\
\hline Median & 17.00 \\
\hline Maximum & 23.00 \\
\hline Minimum & 11.00 \\
\hline Standard Deviation & 2.87 \\
\hline
\end{tabular}

Furthermore, the performance of a Test for one mean $(t=-4.025$ and Sig $=0.000)$ leads us to reject that the mean of the variable LOT- $\mathrm{R}$ is equal to 18.25 , that is, that the average level of optimism manifested by the managers of the Portuguese port sector is equal to that of the managers of the Brazilian civil construction sector. In particular, the test reaffirms, through the difference of means, that the mean of this variable is lower for the first sample than for the second. Nevertheless, a second Test for one mean $(t=-2.219$ and Sig $=0.029)$ confirms the equality between the level of optimism manifested by the managers of the Portuguese port sector and that of the general Brazilian population.

As regards to the homogeneity of this behaviour, the standard deviation of the LOT-R variable (2.87) suggests that managers in the Portuguese port sector express their optimism with slightly less homogeneity than managers in the Brazilian construction sector - 2.73 (Feitosa, 2010) but more uniformly than the Brazilian common population - standard deviation of 3.76 (Bandeira et al., 2002).

\subsection{Anchoring effect}

Lastly, in the third evaluation instrument, and towards the resolution of the third problem-related question (PQ3a and PQ3b), a preliminary descriptive analysis of the estimates of the two anchored groups suggests the presence of anchoring effect in the sample under analysis: for every question contemplated in the test, the median values of the high-anchored group's (AG) estimates are always higher than those of the group exposed to the low anchor $(\mathrm{Ga})$, with the same thing being observed with the mean values of the two groups (Table 4). This behavior is also reflected in the anchoring indexes registered in each of the five questions, whose values are always higher than 0 .

In addition, the average registered was 0.55 , which means that, in comparison with the calibration group, the median estimates of the managers exposed to the anchors moved about 55\% towards these same values. Thus, the observed average, higher than that recorded by Feitosa (2010) - $0.43-$, is in accordance with the evidence already illustrated by this and other authors (Jacowitz \& Kahneman, 1995; Luppe \& Fávero, 2012), confirming the influence of an arbitrary value on the numerical estimates made by the individuals in the sample.

A more detailed comparative analysis between the influence exerted by the low and high anchors on the estimates of the anchored groups is drawn from their respective transformed estimates (Table 5). In this perspective, the global median of the transformed estimates was 52.04 for the AG (high anchor) group, and 44.74 for the $\mathrm{aG}$ (low anchor) group. The deviation of these values to 50 (absence of anchorage) indicates the proportion of the effect. Such values indicate that, as noted by Feitosa (2010), the anchoring effect displayed by the surveyed managers is greater when confronted with low anchors that when confronted with high anchors.

Table 5. Transformed Statistics (AI)

\begin{tabular}{|c|c|c|c|c|}
\hline \multirow{2}{*}{} & \multicolumn{2}{|l|}{ High Anchor $(n=44)$} & \multicolumn{2}{c|}{ Low Anchor $(n=33)$} \\
\cline { 2 - 5 } & Mean & Median & Mean & Median \\
\hline $\mathrm{Q}_{1}$ & 53.39 & 52.30 & 41.61 & 50.26 \\
\hline $\mathrm{Q}_{2}$ & 48.83 & 50.06 & 35.05 & 34.13 \\
\hline $\mathrm{Q}_{3}$ & 58.39 & 62.00 & 43.36 & 45.00 \\
\hline $\mathrm{Q}_{4}$ & 70.41 & 70.37 & 36.90 & 35.40 \\
\hline $\mathrm{Q}_{5}$ & 48.72 & 51.37 & 30.58 & 25.00 \\
\hline Median & \multicolumn{2}{|c|}{52.04} & \multicolumn{2}{c|}{44.74} \\
\hline Mean & \multicolumn{2}{|c|}{57.14} & \multicolumn{3}{c}{35.96} \\
\hline
\end{tabular}

Table 4. Anchoring indexes (AI)

\begin{tabular}{|c|c|c|c|c|c|c|c|c|c|}
\hline & \multicolumn{2}{|c|}{ Anchors } & \multicolumn{6}{|c|}{ Groups } & \multirow{3}{*}{$\mathrm{AI}$} \\
\hline & \multirow[t]{2}{*}{ High } & \multirow[t]{2}{*}{ Low } & \multicolumn{2}{|c|}{$\begin{array}{c}\text { Calibration } \\
(n=41)\end{array}$} & \multicolumn{2}{|c|}{$\begin{array}{l}\text { High-Anchored } \\
\quad(n=44)\end{array}$} & \multicolumn{2}{|c|}{$\begin{array}{l}\text { Low-Anchored } \\
\quad(n=33)\end{array}$} & \\
\hline & & & Mean & Median & Mean & Median & Mean & Median & \\
\hline $\mathrm{Q}_{1}$ & 7,000 & 400 & 8,702 & 2,000 & 8,652 & 6,500 & 2,724 & 2,500 & 0.61 \\
\hline $\mathrm{Q}_{2}$ & 11,200 & 3,200 & 33,750 & 8,000 & 9,301 & 9,000 & 6,664 & 6,000 & 0.38 \\
\hline $\mathrm{Q}_{3}$ & 500 & 300 & 410 & 400 & 493 & 520 & 377 & 375 & 0.73 \\
\hline $\mathrm{Q}_{4}$ & 1,900 & 100 & 875 & 700 & 1,802 & 1,800 & 604 & 500 & 0.72 \\
\hline $\mathrm{Q}_{5}$ & 300 & 25 & 245 & 90 & 218 & 225 & 75 & 130 & 0.35 \\
\hline & & & & & & & & Mean: & 0.55 \\
\hline
\end{tabular}


These observations were verified by performing MannWhitney U Tests for equality of two independent distributions (Questions 1, 2, 4 and 5 with $\mathrm{Z}=-6.146$ and Sig $=$ $0.000, Z=-4.509$ and $\operatorname{Sig}=0.000, Z=-7.190$ and $\operatorname{Sig}=$ 0.000 , and $Z=-5.792$ and $\operatorname{Sig}=0.000$, respectively), as well as a Test for equality of two means from independent samples (Question 3, with $=5.608$ and Sig =0.000).

Finally, a summary of the obtained and analysed results, as well as their relation with the objectives and problem-related questions initially set out, can be consulted in Table 6.

\section{Recommendations}

Despite the limitations so far addressed, human judgment is perfectly useful most of the time. It is not, however, infallible, so it becomes important to study and consider its weaknesses. According to Simon (1983), only in this way can we devise ways of effectively use the powers and capacities that human reasoning gives us. In this sense, the key question, which also solves the third objective of this work, is: what can we do to correct such deficiencies?

With regard to overconfidence and optimism, authors suggest that the elimination or at least reduction of its effects might be achieved through the simple task of asking managers to consider the opposite option to their preferred one (Haran et al., 2010). According to Koriat et al. (1980), interventions that force individuals to reflect on alternative perspectives, interpretations or hypotheses are, in most cases, effective in that they introduce a higher level of realism to the decision maker's thinking.

Similarly, the anchoring effect also seems to be reduced when the individual is induced to look for evidence that contradicts their judgments (Mussweiler et al., 2000). In addition, it also seems to be beneficial to seek to frame problems and scenarios in a more neutral way (Hammond et al., 1999). This means, for example, transforming the problem into an issue that does not insinuate the desired solution. Furthermore, the framing of problems can also be tested by introducing different perspectives and hence different starting points.

In order to mitigate the effects not only of the three biases addressed in this paper but also of the many others already documented in the literature, based on research results, several measures can be applied to improve quality of the decisions to be made:

Using decision-analysis tools. Considering that the human mind is not programmed to make optimal decisions intuitively or automatically, it is preferable to resort to procedures that lead us to more optimized decisions

Table 6. Synthesis of interrelationships between objectives, PQs and results

\begin{tabular}{|c|c|c|}
\hline Objectives & Problem-related Questions & Results \\
\hline \multirow{3}{*}{$\begin{array}{l}\text { Objective } 1 \text { - } \\
\text { To diagnose } \\
\text { the presence of } \\
\text { overconfidence, } \\
\text { optimism and } \\
\text { anchoring effect in } \\
\text { managers of the port } \\
\text { sector. }\end{array}$} & $\begin{array}{l}\text { PQ1a - "Are managers in the } \\
\text { Portuguese port sector susceptible to } \\
\text { the overconfidence bias?" }\end{array}$ & $\begin{array}{l}\text { Port sector managers exhibit significant overconfidence regarding } \\
\text { the accuracy of their own judgments. }\end{array}$ \\
\hline & $\begin{array}{l}\text { PQ2a - "Are managers in the } \\
\text { Portuguese port sector susceptible to } \\
\text { an optimism bias?" }\end{array}$ & $\begin{array}{l}\text { The managers of the Portuguese port sector are significantly } \\
\text { optimistic. }\end{array}$ \\
\hline & $\begin{array}{l}\text { PQ3a - "Are managers in the } \\
\text { Portuguese port sector susceptible to } \\
\text { an anchoring effect bias?" }\end{array}$ & $\begin{array}{l}\text { The numerical estimates produced by managers of the Portuguese } \\
\text { port sector are significantly influenced by the anchors they are } \\
\text { exposed to. }\end{array}$ \\
\hline $\begin{array}{l}\text { Objective } 2 \text { - To } \\
\text { establish comparative } \\
\text { links with the } \\
\text { bibliographic } \\
\text { conclusions } \\
\text { regarding managers } \\
\text { of the Brazilian } \\
\text { construction sector. }\end{array}$ & $\begin{array}{l}\text { PQ1b, PQ2b and PQ3b }-(\ldots) \text { How do } \\
\text { its effects compare with those observed } \\
\text { in the Brazilian construction sector? }\end{array}$ & $\begin{array}{l}\text { 1. The managers of the Portuguese port sector behave in a similar } \\
\text { way to the managers of the Brazilian construction sector in } \\
\text { regards to the confidence they place in their judgments, as well } \\
\text { as showing confidence estimates more homogeneous than the } \\
\text { accuracy of their knowledge; } \\
\text { 2. As far as their optimism is concerned, the managers of both } \\
\text { sectors show the presence of biased thinking, although this is } \\
\text { statistically less expressive in the managers of the Portuguese port } \\
\text { sector; } \\
\text { 3. Managers from both sectors produce biased judgments } \\
\text { regarding the anchors to which they are exposed to, with both } \\
\text { managers of the Portuguese port sector and managers of the } \\
\text { Brazilian construction sector being significantly more influenced } \\
\text { by low anchors. }\end{array}$ \\
\hline $\begin{array}{l}\text { Objective } 3 \text { - In } \\
\text { the presence of } \\
\text { any of the three } \\
\text { biases under } \\
\text { analysis, to provide } \\
\text { guidelines and } \\
\text { recommendations } \\
\text { to mitigate their } \\
\text { impacts. }\end{array}$ & \multicolumn{2}{|c|}{$\begin{array}{l}\text { Objective dependent on the results of the previous problem-questions, and of a qualitative and } \\
\text { bibliographical research character, therefore not inferring the existence of a problem-related question. Its } \\
\text { development appears in the following section (5.4 Recommendations). }\end{array}$} \\
\hline
\end{tabular}


(e.g. linear models) when faced with problems in which the quality of the decision is fundamental. This type of approach (usually multi-attribute) requires the quantification of preferences and relative values that the decision maker deposits in each of the decision options, as well as the prediction of probabilities associated with future events whose results are uncertain. The advantage of applying these tools stems from the fact that, contrary to what happens with human judgment; linear models only analyze information that is empirically proven to have predictive power. Decisions always based on the same set of variables, such as some decisions at the financial level, personnel management or even at the purchasing level, are some of the decisions indicated for the use of linear models.

Acquiring knowledge. Kagel and Levin (1986), among other authors, believe that the process of improving our judgment occurs naturally as we receive feedback on our past decisions. Tversky and Kahneman (1986) state, however, that it is unlikely that the basic biases of judgment will self-correct over time. For the authors, proper learning requires immediate and accurate feedback, which is rarely observed in the real world. In addition, some authors point out that even when receiving instant feedback, man tends to misrepresent the memories of his predictions (Meyvis et al., 2010). For this reason, Neale and Northcraft (1989) suggest that the bias in decision making should be eliminated not by experience (i.e. mere repeated receipt of feedback) but by the acquisition of knowledge. This knowledge results from individuals developing a strategic conceptualization of what constitutes a rational decisionmaking process and learning to identify the biases that limit their rationality.

Eliminate de-biasing. At individual, group and even organizational level, many behaviors are rooted as a standard repository and are therefore difficult to change. Satisfaction with the status quo, risk aversion and a preference for certain results of already known behaviors in favor of uncertain results of innovative behaviors are some of the factors that prevent individuals from changing their behavior. Thus, in order to observe an improvement in decision making and to maintain it over time, it is imperative that rooted thinking and behavior must be unfreezing. Then, once past behaviors are thawed, individuals become more receptive to considering new alternatives (change). After a positive change has been made, and although it is tempting to revert to past practices, new habits should be "frozen" as a new standard behavior of the individual (refreezing). This does not mean that biases cease to exist, since it is still easy for them to be accidentally used, so for this change to be definitive it is necessary for individuals to routinely analyze their decisions, particularly in the search for evidence of biases.

Reasoning analogously. Unlike what happens with learning from individual episodes, the process of extracting common lessons between two or more situations generates a more general understanding, serving as a simple and useful approach to mitigate bias in human judgment
(Thompson et al., 2000). Additionally, a more diversified analog exercise can also be effective in obtaining greater knowledge and, consequently, a better understanding of what is the most appropriate strategy for a given situation and why. Bazerman and Moore (2013) warn, however, that an overly diversified analysis may also lead to the message or lesson to be retained being lost.

Adopting the perspective of an outsider. Kanheman and Lovallo (1993) argue that we all have two perspectives in decision-making, an insider perspective (i.e. the biased decision maker, who considers each situation as unique) and an outsider perspective (able to create generalizations between situations and identify similarities). The authors argue that the outsider makes better decisions than the insider, since the perspective of the former incorporates a greater amount of useful information extracted from previous decisions. Even so, although the two perspectives coexist simultaneously, the human being exhibits a natural tendency to act more in line with the insider, largely because of factors such as overconfidence and optimism. For this reason, and in order to mitigate the effect of such biases, Kahneman and Lovallo (1993) suggest that the decision-maker invite the outsider to share his or her vision with him or her, which may arise in the form of a trusted friend or colleague with experience in similar decisions. Alternatively, the decision-maker himself can and should also assume the role of outsider, wondering what advice he would give to someone who asks him the question he seeks to resolve. The key idea of the strategy is therefore to give more prominence to the outsider's opinion and not allow the insider to make all the decisions alone, especially on sensitive and important issues.

Understanding biases in others. The nature of management means that individuals are constantly working with and on the basis of others' decisions. In this sense, Bazerman and Moore (2013) present a model that allows, above all, adjusting a multitude of biased decisions in both individual and collective contexts: (1) understand and analyze the context in which decisions are being made, (2) distinguish potential biases surrounding decisions and decision makers, and (3) identify and make logical adjustments for each decision.

Referring people to more ethical and sensible decisions. Thaler and Benartzi (2004) argue that it is possible to anticipate the mistakes that human beings make on a regular basis and build systems that correct such behaviors in order to lead individuals to more correct and ethical decisions (e.g. assumed organ donation policy for transplants imposed in several European countries).

Improving our decision making is, however, a complex task, which occurs gradually and only with persistent monitoring from the person's side. It requires, therefore, time, effort and courage from the organizations to recognize the limitations of their decision-makers in order to replace, whenever needed and justified, the primary use of a faulty intuition by a strategy of collecting and analysing truly appropriate information. 


\section{Conclusions}

The results of the present investigation confirm that managers in the Portuguese port sector are also susceptible to cognitive biases which, in turn, result in judgment errors in a systematic and predictable way. In particular, and in a comparison with the observations documented by Feitosa (2010), the application of diagnosis tools made it possible to verify that: (1) as seen with managers of the Brazilian civil construction sector, managers of the Portuguese port sector are also overconfident in regard to their knowledge and skills; (2) managers in the Portuguese port sector are considerably optimistic about their future, albeit less significantly than managers in the Brazilian construction industry, and (3) the introduction of anchors considerably influences the judgments of managers in both economic groups. Thus, the obtained results refute the foundations of rational theories that act as the basis for many of the decision-making models currently accepted. Instead, evidence that the managers under analysis do in fact display biased behaviour suggest that reality is closer to the principles of bounded rationality. This is not, however, to suggest that managers are less clever, but rather to recognize that they are, first most, human beings, and that like all other individuals they are prone to rely on simple heuristics and routine reasoning when making decisions.

In the light of the above findings, the present study aimed to contribute to the advancement of the literature on the limitations of rationality in the organizational decision-making process, namely by the diagnosis of three prominent biases in the Portuguese port sector reality, a still relatively undocumented topic in the national context, as well as drawing comparisons of behaviour with another sector. Moreover, this article also provided a set of measures that can contribute to the mitigation of the detrimental effects of biases and, consequently, to the improvement of the decisions made by these and other managers all around the world. It is, however, important to safeguard that the conclusions of the present study, drawn from a non-probabilistic sample, are exclusive for the sample itself and should therefore be read carefully, avoiding direct transpositions to other economic groups or organizations. For that reason, it is suggested, in terms of future research, the expansion of the theme through the application of one or more of the addressed evaluation instruments in new contexts, both at organizational level (i.e. different companies of different) and at sectoral level.

\section{References}

Alpert, M., \& Raiffa, H. (1982). A progress report on the training of probability assessors. In D. Kahneman, P. Slovic, \& A. Tversky (Eds.), Judgment under uncertainty: Heuristics and biases (pp. 294-305). Cambridge University Press. https://doi.org/10.1017/CBO9780511809477.022

ADC (2015). Estudo sobre a concorrência no setor portuário (Consulta pública, Julho). Autoridade da Concorrência. http://www. concorrencia.pt/vPT/Noticias_Eventos/ConsultasPublicas/ Documents/Estudo_Setor\%20Portu\%C3\%A1rio_ENQUAD-
RAMENTO\%20DA\%20CONSULTA\%20P\%C3\%9ABLICA. pdf

Baker, M., \& Wurgler, J. (2004). A catering theory of dividends. The Journal of Finance, 59(3), 1125-1166. https://doi.org/10.1111/j.1540-6261.2004.00658.x

Bandeira, M., Bekou, V., Lott, K., Teixeira, M., \& Rocha, S. (2002). Validação transcultural do Teste de Orientação da Vida (TOV-R). Estudos da Psicologia, 7(2), 251-258. https://doi.org/10.1590/S1413-294X2002000200006

Bazerman, M., Curhan, J., Moore, D., \& Valley, K. (2000). Negotiation. Annual Review of Psychology, 51(1), 279-314. https://doi.org/10.1146/annurev.psych.51.1.279

Bazerman, M., \& Moore, D. (2013). Judgment in managerial decision making ( $8^{\mathrm{a}}$ ed.). Wiley.

Bi, Y., Dang, Q., Li, S., Guo, J., \& Zhang, B. (2016). The effect of overconfidence on persistent behaviour: The mediation effect of "I think I can do it" rather than "I'm attracted to it". Psychological Reports, 118(1), 138-153.

https://doi.org/10.1177/0033294115627524

Buehler, R., Griffin, D., \& Ross, M. (1994). Exploring the "planning fallacy": Why people underestimate their task completion times. Journal of Personality and Social Psychology, 67(3), 336-381. https://doi.org/10.1037/0022-3514.67.3.366

DeBondt, W., \& Thaler, R. (1995). Financial decision-making in markets and firms: A behavioural perspective. In R. A. Jarrow, V. Maksimovic, \& W. T. Ziemba (Eds.), Handbooks in OR \& MS (pp. 385-410). Elsevier. https://doi.org/10.1016/S0927-0507(05)80057-X

Dedu, V., Turcan, C., \& Turcan, R. (2012). An introduction to behavioural corporate finance. Annuals of the University of Oradea, Economic Science Series, 21(2), 471-476.

Epley, N. (2004). A tale of tuned decks? Anchoring as accessibility and anchoring as adjustment. In D. J. Koehler \& N. Harvey (Eds.), Blackwell handbook judgment and decision making (pp. 240-256). Blackwell. https://doi.org/10.1002/9780470752937.ch12

Fairchild, R. (2005). The effect of managerial overconfidence: Asymmetric information, and moral hazard on capital structure decisions. Institute of Chartered Financial Analysts of India (ICFAI) Journal of Behavioural Finance, 2(4), 46-68. https://doi.org/10.2139/ssrn.711845

Feitosa, A. (2010). Excesso de confiança, otimismo e ancoragem em gestores da construção civil no brasil: Estudo de caso da Camargo Correa (Unpublished master's thesis). ISCTE Business School, Lisbon.

Fischhoff, B., Slovic, P., \& Lichtenstein, S. (1977). Knowing with certainty: The appropriateness of extreme confidence. Journal of Experimental Psychology: Human Perception and Performance, 3(4), 552-564. https://doi.org/10.1037/0096-1523.3.4.552

Frank, R. (2010). Microeconomics and behaviour ( $8^{\text {th }}$ ed.). McGraw-Hill.

Galinsky, A. D., \& Mussweiler, T. (2001). First offers as anchors: The role of perspective-taking and negotiator focus. Journal of Personality and Social Psychology, 81(4), 657-669. https://doi.org/10.1037/0022-3514.81.4.657

Gigerenzer, G., Hoffrage, U., \& Kleinbölting, H. (1991). Probabilistic mental models: A Brunswikian theory of confidence. Pyschological Review, 98(4), 506-528. https://doi.org/10.1037/0033-295X.98.4.506

Griffin, D., \& Varey, C. (1996). Towards a consensus on overconfidence. Organizational Behaviour and Human Decision Processes, 65(3), 227-231. https://doi.org/10.1006/obhd.1996.0023 
Gunia, B., Swaab, R., Sivanathan, N., \& Galinsky, A. (2013). The remarkable robustness of the first-offer effect: Across culture, power, and issues. Personality and Social Psychology Bulletin, 39(12), 1547-1558.

https://doi.org/10.1177/0146167213499236

Hackbarth, D. (2004). Managerial traits and capital structure decisions. Journal of Financial and Quantitative Analysis, 43(4), 843-882. https://doi.org/10.1017/S002210900001437X

Hammond, J., Keeney, R., \& Raiffa, H. (1999). Smart choices: A practical guide to making better life decisions. Broadway.

Haran, U., Moore, D. A., \& Morewedge, C. (2010). A simple remedy for overprecision in judgment. Judgment and Decision Making, 5(7), 467-476.

https://doi.org/10.1037/e615882011-200

Heaton, J. B. (2002). Managerial optimism and corporate finance. Financial Management, 31(2), 33-45. https://doi.org/10.2307/3666221

INE (2016). Estatísticas dos Transportes e Comunicações (Edição 2017). Instituto Nacional da Estatística. http://www.concorrencia.pt/vPT/Noticias_Eventos/ConsultasPublicas/Documents/Estudo_Setor\%20Portu\%C3\%A1rio_ENQUADRAMENTO\%20DA\%20CONSULTA\%20P\%C3\%9ABLICA.pdf

Jacowitz, K. E., \& Kahneman, D. (1995). Measures of anchoring in estimation tasks. Personality and Social Psychology Bulletin, 21(11), 1161-1166. https://doi.org/10.1177/01461672952111004

Kagel, J. H., \& Levin, D. (1986). The winner's curse and public information in common value auctions. The American Economic Review, 894-920.

Kahneman, D., \& Lovallo, D. (1993). Timid choices and bold forecasts: A cognitive perspective on risk taking. Management science, 39(1), 17-31. https://doi.org/10.1287/mnsc.39.1.17

Klayman, J., Soll, J. B., González-Vallejo, C., \& Barlas, S. (1999). Overconfidence: It depends on how, what, and whom you ask. Organizational Behavioral and Human Decision Process, 79(3), 216-247. https://doi.org/10.1006/obhd.1999.2847

Koriat, A., Lichtenstein, S., \& Fischhoff, B. (1980). Reasons for confidence. Journal of Experimental Psychology: Human Learning and Memory, 6(2), 107-118. https://doi.org/10.1037/0278-7393.6.2.107

Libby, R., Rennekamp, K. (2012). Self-serving attribution bias, overconfidence, and the issuance of management forecasts. Journal of Accounting Research, 50(1), 197-237. https://doi.org/10.1111/j.1475-679X.2011.00430.x

Luppe, M. R., \& Fávero, L. (2012). Anchoring heuristic and the estimation of accounting and financial indicators. International Journal of Finance and Accounting, 1(5), 120-130.

Malmendier, U., \& Tate, G. (2015). Behavioural CEOs: The role of managerial overconfidence. Journal of Economic Perspectives, 29(4), 37-60. https://doi.org/10.1257/jep.29.4.37

Malmendier, U., Tate, G., \& Yan, J. (2011). Overconfidence and early-life experiences: The effect of managerial traits on corporate financial policies. Journal of Finance, 66(5), 1687-1733. https://doi.org/10.1111/j.1540-6261.2011.01685.x

Meyer, W. G. (2014). The effect of optimism bias on the decision to terminate failing projects. Project Management Journal, 45(4), 7-20. https://doi.org/10.1002/pmj.21435
Meyvis, T., Ratner, R. K., \& Levav, J. (2010). Why don't we learn to accurately forecast feelings? How misremembering our predictions blinds us to past forecasting errors. Journal of Experimental Psychology: General, 139(4), 579. https://doi.org/10.1037/a0020285

Mussweiler, T., Strack, F., \& Pfeiffer, T. (2000). Overcoming the inevitable anchoring effect: Considering the opposite compensates for selective accessibility. Personality and Social Psychology Bulletin, 26(9), 1142-1150. https://doi.org/10.1177/01461672002611010

Neale, M. A., \& Northcraft, G. B. (1989). Behavioral negotiation theory: a framework for conceptualizing dyadic bargaining. Northwestern University.

Nofsinger, J. R. (2005). The psychology of investing (2 ${ }^{\text {nd }}$ ed.). Prentice Hall.

Schade, C., \& Koellinger, P. (2007). Heuristics, biases, and the behaviour of entrepreneurs. In M. Minniti (Ed.), Entrepreneurship: The Engine of Growth, 1, 41-63. Praeger.

Scheier, M. F., \& Carver, C. S. (1988). A model of behavioural self-regulation: Translating intention into action. In L. Berkowitz (Eds.), Advances in experimental social psychology, 21, 303-346. Academic Press. https://doi.org/10.1016/S0065-2601(08)60230-0

Scheier, M. F., Carver, C. S., \& Bridges, M. W. (1994). Distinguishing optimism from neuroticism (and trait anxiety, selfmastery, and self-esteem) - a re-evaluation of the Life Orientation Test. Journal of Personality and Social Psychology, 67(6), 1063-1078. https://doi.org/10.1037/0022-3514.67.6.1063

Serfas, S. (2011). The impact of cognitive biases on capital investments - Empirical evidence regarding the anchoring heuristic. Zeitschrift fur Planung und Unternehmenssteuerung, 21(4), 427-446. https://doi.org/10.1007/s00187-011-0120-0

Siemiatycki, M. (2010). Managing optimism biases in the delivery of large infrastructure projects: A corporate performance benchmarking approach. European Journal of Transport and Infrastructure Research, 10(1), 30-41.

Simon, H. A. (1983). Reason in human affairs. Standford University Press.

Simon, H. A. (1997). Administrative behaviour ( $4^{\text {th }} \mathrm{ed}$.). The Free Press.

Thaler, R. H. (2005). Advances in behavioural finance. Princeton University Press.

Thaler, R. H. (2016). Comportamento inadequado: A construção da economia comportamental. Actual.

Thaler, R. H., \& Benartzi, S. (2004). Save more tomorrow ${ }^{\mathrm{Tm}}$ : Using behavioral economics to increase employee saving. Journal of political Economy, 112(S1), S164-S187. https://doi.org/10.1086/380085

Tversky, A., \& Kahneman, D. (1974). Judgment under uncertainty: Heuristics and biases. Science, 185(4157), 1124-1131. https:/doi.org/10.1126/science.185.4157.1124

Tversky, A., \& Kahneman, D. (1986). Judgment under uncertainty: Heuristics and biases. Judgment and Decision Making: An Interdisciplinary Reader, 38-55.

Weinstein, N. D. (1980). Unrealistic optimism about future events. Journal of Personality and Social Psychology, 39(5), 806-820. https://doi.org/10.1037/0022-3514.39.5.806 